\title{
An Application of Virtual Assessment and Enhanced Testing Methods in Developing of Aerial Pressure Sensor System
}

\author{
Weilin $\mathrm{Li}^{\mathrm{a}}$, Zhiqiang $\mathrm{Li}^{*}$, , Xiaoxiao $\mathrm{Li}^{\mathrm{c}}$, Sha Qin ${ }^{\mathrm{d}}$ \\ Key Laboratory of Reliability and Environmental Engineering, Beihang university, Beijing, China \\ alwl890228@126.com, bleezhq@buaa.edu.cn, ‘guohailtx@163.com, dsjjiitt@163.com
}

\begin{abstract}
The combined application of virtual technology and enhancement testing plays an important role to improve the reliability of avionics products in the design stage. The manufacture processing of static pressure probe is introduced in this paper in which finite element simulation analysis software ANSYS is used to analysis it's structure and some potential design flaws are found, reliability enhancement testing is used to verify the results of simulation and stimulate some other potential design flaws.
\end{abstract}

Keywords-finite element simulation; faults; reliability enhancement testing.

\section{INTRODUCTION}

The development process of military electronic product has strict requirements, prototype development is firmly divided into 4 steps: original design( $F)$, preliminary prototype(C), verify model (S) and the stereotypes(D). Nowadays, the domestic reliable works that a series of reliable test are mainly involved from the step $\mathrm{S}$, aiming on technics problems detecting and a little design defects, then followed by optimizations of design and technology. This procedure will be repetitive and costly, and will delay the developing time seriously. Introducing the reliability concerning in the early stage will make the product itself has a strong internal reliability and reduces the whole cost in the subsequent development. Reliability virtual assessment technology is an attempt in this aspect.

In this paper, the development process of a aerial pressure sensor system equipped in a military aircraft, as the research object, is introduced in phases of reliability virtual assessment and enhancement testing technology. In the design phase while the product is still in the drawing stage, dynamic simulation and thermal analysis are applied with virtual prototyping to find the weak links in the design, and then a preliminary quantitative analysis is carried out by virtual assessment method. Step to the $\mathrm{S}$ phase, reliability enhancement test is applied to verify the simulation analysis result, and further exposed crafts flaws.

By the applying of the two technologies, a number of potential faults have been found, and these will certainly decrease the intrinsic reliability of the product. Update in designing focus on the faults will definitely provide a favorable environment protection for subsequent identification and batch.

\section{RELIABILITY SIMULATION TEST}

Reliability simulation test refers to an analysis process that obtains the response of the products under actual working conditions and environmental conditions, early in the product design phase. And environmental loads that applied to the model include vibration and temperature stress. That makes it possible to found the weak point in the design, which can improve the design as early as possible before the actual production of the product.

The simulation test is a failure of physical technology. This method bases on the failure of the physical model of the components and the typical structure and makes the component-level and system-level assessment. This concept was first proposed in 1992 in the United States, and rapid developed since 1997. The first application attempt is in the military field, and then it gets promotion in a wide range.

\section{A. Dynamics simulation analysis}

The problem that the dynamics analysis figures out is the response of the time-varying load on the whole structure or parts by considering the role of damping and inertia. And the method of dynamics analyzing includes modal analysis and random vibration analysis. Dynamics simulation of static pressure probe is calculated using ANSYS-Workbench-14.0, and the process of dynamics simulation analysis is developed as follows.

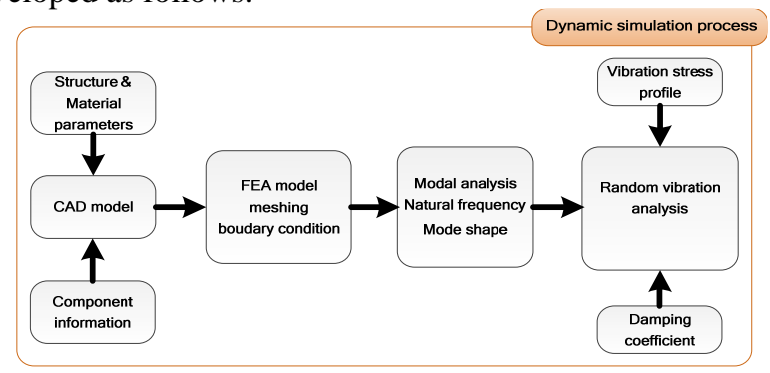

Figure 1. Process of dynamics simulation analysis

The first step of the dynamics simulation analysis is collection of the product's information. According to the Saint-Venant principle, the details in the model are erased 
for simplification. The simplification of CAD model is carried out by CATIA software, in Figure 2.

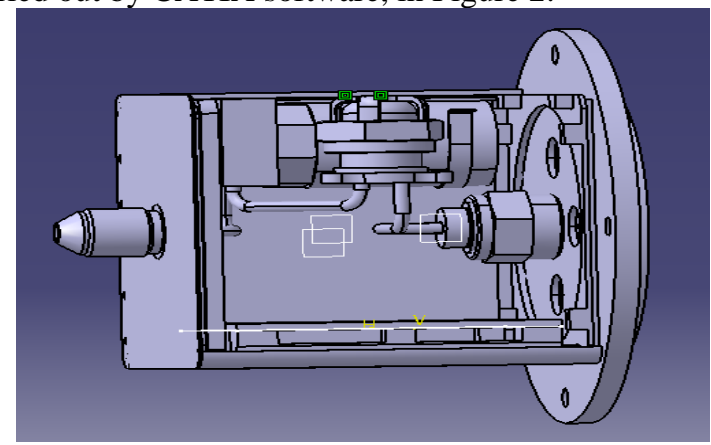

Figure 2. Simplified CAD model of product

Refer to the aircraft working frequency range, the analysis range of frequency define from $10 \mathrm{~Hz}$ to $2000 \mathrm{~Hz}$. Select the first 20 modal orders to analysis. And the calculation result is that the 1st natural frequency of the CPU circuit board is $489.56 \mathrm{~Hz}$; the first natural frequency of the right external mouth is $898.14 \mathrm{~Hz}$, which appeared at the 6th order of the product's modal frequency.

Figure 3 shows that maximum RMS value of Von-mise stress is $53.388 \mathrm{MPa}$. And it appears in external mouth of the right of the sensor pin roots, which is the 105904 node of 39872 unit.

Programming APDL to extract this point's stress response power density curve is showed in Figure 4.

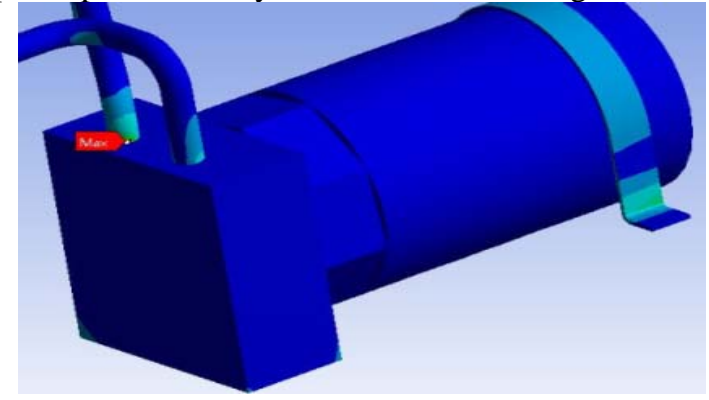

Figure 3. Von-mise’s stress of product

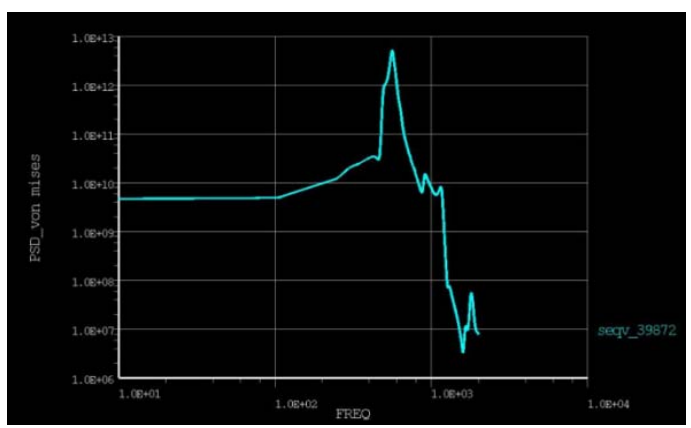

Figure 4. The response PSD of Equivalent unit

The figure shows there is a maximum response at the danger point in the sixth order of frequency, and it also suggests that the design of the right external mouth is not appropriate. Further, reliability enhancement test should be applied to verify the results of the simulation experiment.

\section{B. Analysis of thermal simulation}

The thermal analysis of the electronic device, also known as "thermal simulation", using mathematical analysis method and computer simulation technology, can be used to obtain the electronic device's temperature distribution in the design stage.

The commercial software selected for the thermal analysis is Flotherm, and the thermal analysis process is shown in Figure 5.Establish the CFD digital prototype using 3D CAD data from the digital prototype, combining with collected information of electronic components such as power consumption and packaging, shown in figure 6 .

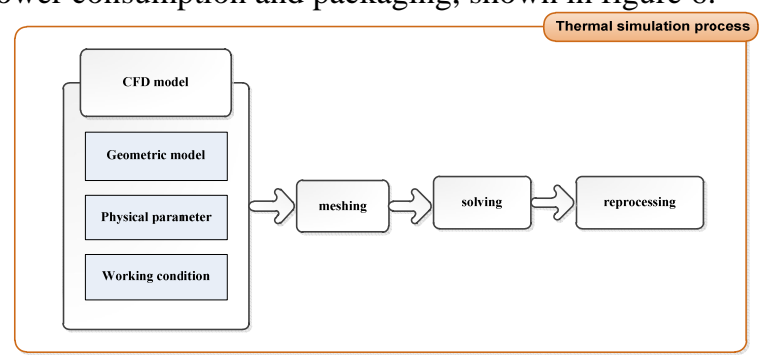

Figure 5. Thermal analysis process of electronic product

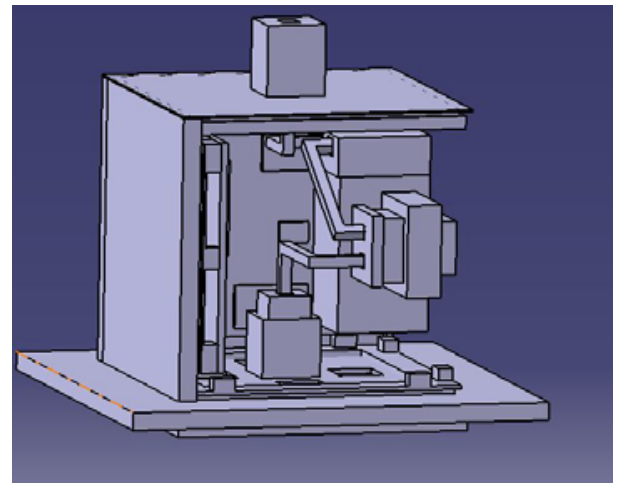

Figure 6. The CFD mode of the product

Under different temperature conditions, the thermal analysis results of the whole product and the printed circuit board are shown in Figure 7 8.
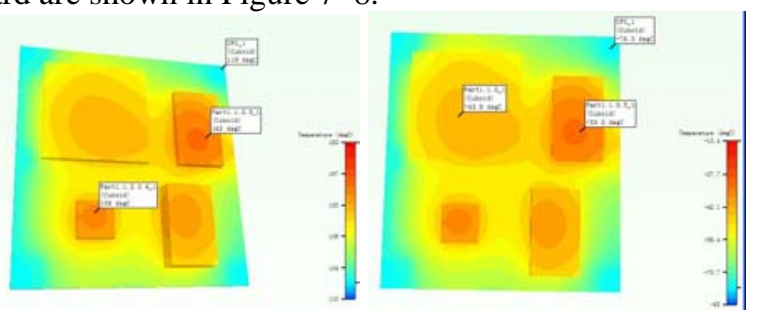

Figure 7. The temperature distribution of CPU in $110^{\circ} \mathrm{C}$ and $-85^{\circ} \mathrm{C}$ 


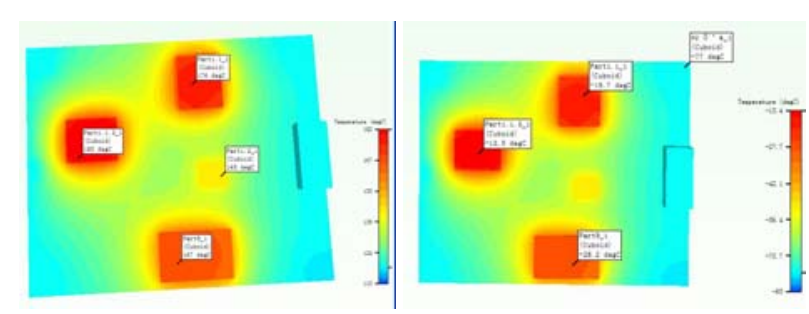

Figure 8. The temperature distribution of power supply board in $110^{\circ} \mathrm{C}$ and $-85^{\circ} \mathrm{C}$

As the product is still in the early stage of design, the results of vibration analysis and thermal analysis can sever as an important basis the design.

\section{Reliability virtual assessment}

In this paper, the hoard-level reliability assessment software CalcePWA is released by Calce Laboratory of the University of Maryland. PWA is the only fault predicted software based on the POF and has been tested in many engineering practices.

These main circuit boards' model are shown in Figure 9.
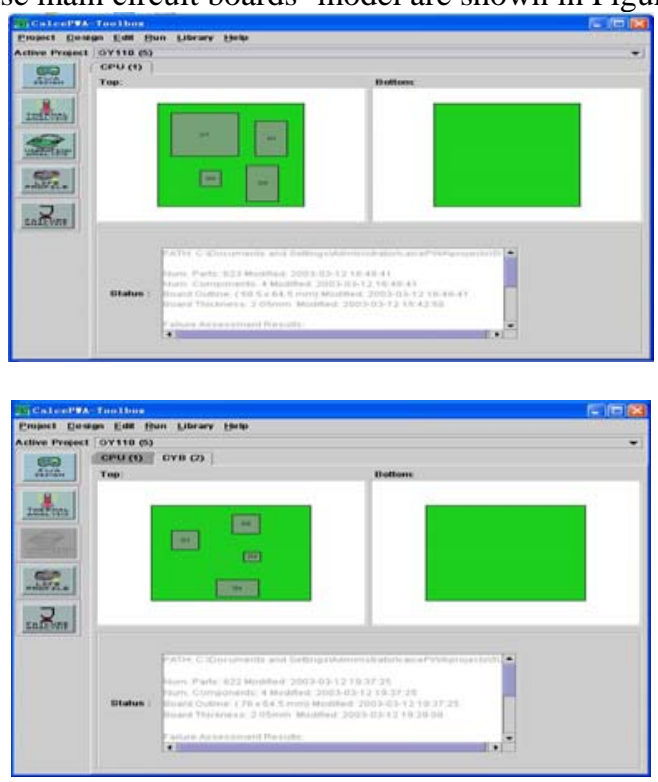

Figure 9. Product's modeling in PWA

In the simulation of Monte Carlo, setting the distribution of crafts parameter for the triangular distribution, simulation times of 1000 , expected failure percentage of $63.2 \%$. By the calculation of the PWA, the fault predicted information of every component is shown in Figure10:
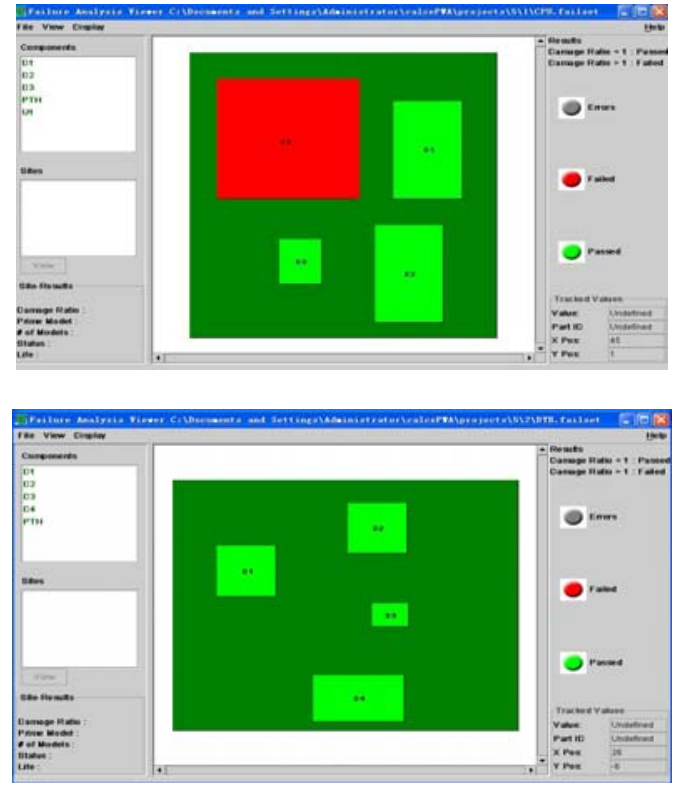

Figure 10. The fault predicted information of every component

By the reliability simulation and virtual assessment, the product is confirmed a higher system-level reliability, but there is still one weak link. The exposed weakness is conductive to the further design and improve the overall level of reliability, some of the weaknesses have been verified in the subsequent enhancement testing.

\section{RELIABILITY ENHANCEMENT TESTING}

The enhancement testing has the same starting point with the reliability simulation testing, the object is to find the shortcomings. This technology is an effective method applied in the $\mathrm{S}$ phase for the testing subject is material object, and it is relatively complemented with simulation testing.

How to make a reliability enhancement testing program is not the key point in this paper, so the Figure 11 shows the process of the test.

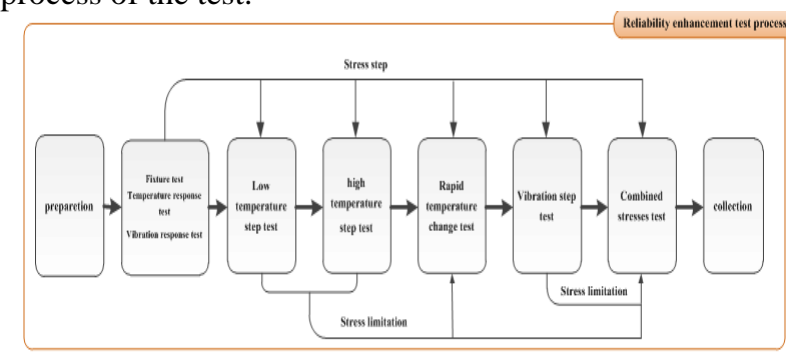

Figure 11. Process of reliability enhancement test

Static pressure probe is installed in the testing chamber as Fig 12 shown. The chamber is combined test chamber. The enhancement testing is carried out according to the program, stop testing whenever there is a fault appears. Record the faults, initiatory analysis and solutions. 


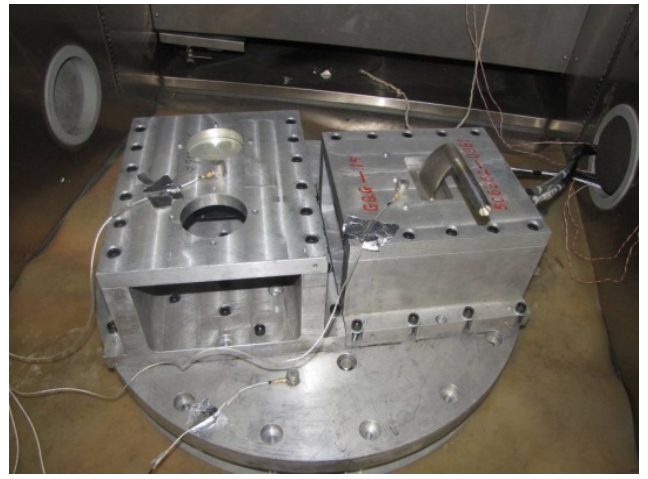

Figure 12. Testing product's installation status

There are three faults during the entire experiment, in the process of vibration step test and combined stress test. There are two faults during the vibration step test: fault lights lit when the vibration magnitude is $18 \mathrm{G}$, while falls to $4 \mathrm{G}$, the same fault, but stop the test, restores the normal working state; in the troubleshooting process of the first fault, the root of the sensor assembly adapter is found broken.

The third fault appears in the second circle and low temperature section of the combined stresses test: the fault lights lit, and all the output data are wrong.

There is a short description of the three faults in the tablet I, and grouped into three categories of responsible fault.

TABLE I. FAULTS COLLECTION

\begin{tabular}{|c|c|c|c|c|}
\hline No & phase & profile & $\begin{array}{c}\text { Fault } \\
\text { phenomenon }\end{array}$ & $\begin{array}{c}\text { Initial } \\
\text { analysis }\end{array}$ \\
\hline 1 & $\begin{array}{l}\text { Vibration } \\
\text { step test }\end{array}$ & $18 \mathrm{G}$ & Fault lights lit & $\begin{array}{c}\text { Sensor } \\
\text { has fault }\end{array}$ \\
\hline 2 & $\begin{array}{l}\text { Vibration } \\
\text { step test }\end{array}$ & $<18 G$ & $\begin{array}{l}\text { The root of the } \\
\text { sensor assembly } \\
\text { adapter break }\end{array}$ & $\begin{array}{l}\text { Airway } \\
\text { pipe } \\
\text { break }\end{array}$ \\
\hline 3 & $\begin{array}{c}\text { Combined } \\
\text { stresses test }\end{array}$ & $\begin{array}{c}-75^{\circ} \mathrm{C}, 7.2 \mathrm{G} \\
28 \mathrm{~V}\end{array}$ & $\begin{array}{c}\text { Fault lights lit, all } \\
\text { the output data are } \\
\text { wrong }\end{array}$ & $\begin{array}{c}\text { CPU has } \\
\text { fault }\end{array}$ \\
\hline
\end{tabular}

For a detailed analysis of the above three faults are described as follows:

(1) The first fault: by measurement and analysis, the fault due to the damage of the pressure sensor. The pressure sensor' analog and frequency output are wrong, so the fault lights lit. The simulation can't find this.

(2) The third fault: by measurement and analysis, due to the CPU pin fractures on the CPU board assembly, resulting in a product does not work properly. This fault verifies the effectiveness of the reliability simulation test.

(3) The second fault: focus on the root of the adapter in the simulation experiment, it has the maximum response in the sixth order frequency of the product. As there was no pipe detection, so the accurate vibration value can't be determined, but the value range for the failure of $4 \mathrm{G}$ to $18 \mathrm{G}$. In view of the vibration simulation test, the RMS value of the product obtained maximum stress response in the root of the sensor.
According to the profile imposed on the product in the reliability enhancement test, vibration stepper steps from 4G to $2 \mathrm{G}$ until 18G. the $\mathrm{G}$ value of each step converts to the PSD input spectrum by calculating, as Figure 13; calculation results are shown in Tablet II:

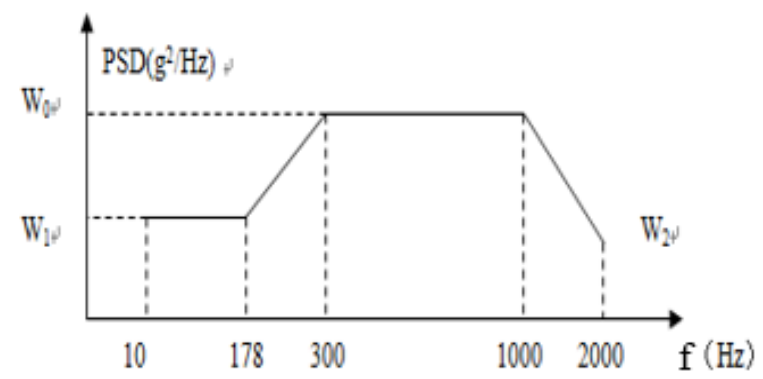

Figure 13. Input spectrum of random vibration

TABLE II. THE RANDOM VIBRATION INPUT SPECTRUM CORRESPONDED TO EACH G

\begin{tabular}{crrc}
\hline $\mathrm{G}$ & W0/10e-3 & W1/10e-3 & W2/10e-3 \\
\hline 4 & 11.66 & 5.83 & 2.915 \\
6 & 26.24 & 13.12 & 6.56 \\
8 & 46.64 & 23.32 & 11.66 \\
10 & 72.88 & 36.44 & 18.22 \\
12 & 104.94 & 52.47 & 26.235 \\
14 & 142.84 & 71.42 & 35.71 \\
16 & 186.56 & 93.28 & 46.64 \\
18 & 236.2 & 118.1 & 59.05 \\
\hline
\end{tabular}

The material of right external mouth is copper and zinc alloy, by inquiring China aeronautical materials handbook: $\sigma_{b}=390 M P, \sigma^{-1}=155 M P a$.

The equivalent stress of danger node and unit on every $\mathrm{G}$ value statistics in the Tablet III:

TABLE III. THE STATISTICS OF STRESS VALUE TO EACH G

\begin{tabular}{cccc}
\hline $\mathrm{G}$ & W0/10e-3 & W1/10e-3 & W2/10e-3 \\
\hline 4 & 11.66 & 5.83 & 2.915 \\
6 & 26.24 & 13.12 & 6.56 \\
8 & 46.64 & 23.32 & 11.66 \\
10 & 72.88 & 36.44 & 18.22 \\
12 & 104.94 & 52.47 & 26.235 \\
14 & 142.84 & 71.42 & 35.71 \\
16 & 186.56 & 93.28 & 46.64 \\
18 & 236.2 & 118.1 & 59.05 \\
\hline
\end{tabular}

The root of sensor does not reach the destructive stress of the material from $4 \mathrm{G}$ until $18 \mathrm{G}$, but reach the fatigue limit strength of the material in 10G, in 12G until 18G has reached the intensity of the fatigue limit of 2.3 times. 
Improved product has no fault in the regression enhancement test, the ability of resistance to environmental stress exceeds the maximum value and the reliability of the product has been greatly proved.

\section{CONCLUSIONS}

(1) Reliability simulation test locates the weak links of the product, and the enhancement test verifies the result of simulation. These two reliability technologies play a key role in design.

(2) By the verification of enhancement test, the reliability simulation test and virtual assessment technology can provide the Qualitative analysis and quantitative analysis about the weak links of the product.

\section{REFERENCES}

[1] MIL-HDBK-217F, Reliability Prediction of Electronic Equipment. US Department of Defense, Fedition, 1995.

[2] James G. McLeish, Enhancing MIL-HDBK-217 Reliability Predictions with Physics of Failure Methods.
[3] B. Foucher, D. Das, J. Boullie and B.Meslet, A review of reliability prediction methods for electronic devices, Microelectronics Reliability, 2002, 1155-1162.

[4] Robin Alastair Amya, Guglielmo S. Agliettia, and Guy Richardsonb, Reliability analysis of electronic equipment subjected to shock and vibration - A review, Shock and Vibration,2009

[5] Neville Sachs, Root couse failure analysis-interpretation of fatigue failure, reliability magazine, 1996.

[6] J. Pitarresi, P. Geng, W. Beltman and Y. Ling, Dynamic modeling and measurement of personal computer motherboards. 52nd Electronic Components and Technology Conference, 2002, 597-603.

[7] R. Li, A methodology for fatigue prediction of electronic components under random vibration load, ASME Journal of Electronic Packaging, 2001, 394-400.

[8] J. Pitarresi, D. Caletka, R. Caldwell and D. Smith, The smeared property technique for the FE vibration analysis of printed circuit cards, ASME Journal of Electronic Packaging 113 (1991), 250-257.

[9] A.O. Cifuentes, Estimating the dynamic behavior of printed circuit boards, IEEE Transactions on Components, Packaging, and Manufacturing Technology Part B: Advanced Packaging 17(1) (1994), 69-75.

[10] F. Jensen, Electronic Component Reliability, Wiley, 1995. 